Dae-Won Seo

Kwang-Leol Jeong

$\underline{\text { http://dx.doi.org/10.21278/brod70103 }}$

ISSN 0007-215X

eISSN 1845-5859

\title{
NUMERICAL STUDY ON THE PREDICTION OF THE BOW FLARE SLAMMING PRESSURE FOR THE CONTAINER SHIP IN REGULAR WAVE
}

UDC 629.544:629.5.017.2:629.5.024.31

Original scientific paper

\begin{abstract}
Summary
A container ship has large flare on the bow flare region to accommodate more container recently. This flare region experiences the impact pressure due to slamming phenomenon under rough sea conditions. The impact pressure is transferred to the hull structure and the impact pressure causes structural damage. A strength assessment of the bow region is evaluated based on the empirical formulas according to various classifications. In this study, the numerical simulations were performed to compare with empirical method, and predict the bow flare slamming pressure on the container ship. It is found that the bow flare slamming pressure generated up to $625 \mathrm{kPa}$ near 0.975 station and the bow flare slamming pressure obtained from the formulas of the CSR and ABS tend to be similar to the CFD results.
\end{abstract}

Key words: $\quad$ Slamming load; bow flare slamming; impact pressure; container ship; $C F D ; K C S$.

\section{Introduction}

Ships operated under rough sea conditions encounter repetitive load by relative motion against the waves from stem to stern. In the process of entering into water, the ship structure is temporarily subjected to the impact pressure. The impact pressures are categorized into bow flare slamming, bottom slamming, stern slamming, and green water loading depending on the position where the impact occurs, and various studies have been carried out through calculations and model experiments. In general, bow flare slamming occurs often in large container ships with a large flare angle, while stern slamming frequently occurs on LNGCs since they have a relatively wide stern, and bottom slamming occurs in tankers because they have blunt stems. Repeatedly applied impact pressure causes structural damage and affects the stability of the vessel.

Hence it is important to estimate the impact load of the slamming phenomenon. Von Karman [1] and Wagner [2] have tried to find an asymptotic solution to the slamming pressure 
on a $2 \mathrm{D}$ circular cylinder and wedge shapes long ago. Since then, studies based on the potential flow have been conducted to predict the slamming impact pressure by Dobrovol'skaya [3], Zhao and Faltinsen [4], and Muzaferija et al. [5]. However, there is a difficulty in simulating the breaking wave using the potential code when the free surface hits the hull structure. Since then, many studies have tried to estimate the slamming impact pressure including breaking wave by model experiments and Computational Fluid Dynamics (CFD). Wang et al. [6] measured the slamming pressure through a model experiment on drop test of a wedge and tried to investigate the relationship between slamming pressure and dead rise angle. Various studies have been conducted recently, and Hong et al. [7] have examined the model experiment of the drop test on the 2D wedge section and the 2D bow section in particular. Hong et al. [8] also conducted a model experiment to measure bow flare slamming on container ships in regular and irregular waves.

Wang and Soares $[9,10]$ confirmed that numerical results on slamming pressure agree well with those of drop tests of the wedge through a model experiment. Lee and Lew [11], Kim et al. [12] and Rahaman et al.[13] conducted the calculation using CFD on an LNG carrier and container ship. However, it is still difficult to accurately estimate the impact pressure through numerical simulations, because the slamming pressure occurs suddenly and disappears in a matter of seconds. In particular, it is necessary to keep the time interval sufficiently small in $\mathrm{CFD}$, and the total time of calculation increases significantly.

A significant motion of the vessel and intense free water surface have to be calculated accurately to obtain reliable slamming load. Although studies, which predicted the slamming pressure were conducted often under irregular wave conditions in full scale $[14,15]$, this is deemed impractical to be applied to the design phase considering the calculation time for simulation. Therefore, simplifications of irregular waves to regular waves under head sea conditions, and simplified interpretations using incident waves have become common [16].

The subject vessel of this study is the the KRISO container ship (KCS) with various experimental data. Recently, experimental results of added resistance in regular waves were published at a CFD workshop held in Japan in 2015, and they were widely used for verification of numerical simulation. Unfortunately, experiments for measuring slamming pressure have not been performed yet, and the results of this numerical study are expected to be the basis of comparable data in terms of prediction of slamming load.

The slamming pressure from the numerical simulation was directly compared with the rule formula proposed by various classification society. These results are expected to be the database for the revision of slamming load formulas in the future.

\section{Numerical setup and calculation conditions}

The target vessel is the KCS container with a length of $230 \mathrm{~m}$. The simulation can be conducted on the full scale, but present numerical simulations were performed on a model scale considering number of grid, calculation time and accuracy. The longitudinal centre of gravity (LCG) is $111.6 \mathrm{~m}$ based on AP and the vertical centre (VCG) of gravity is $14.322 \mathrm{~m}$ above the keel (Table 1).

A grid generation and numerical simulation were carried out using a commercial code STAR-CCM+ Version 11.06. The trimmed mesh method of STAR-CCM+ has the advantage because the mesh size can be set either relatively small for complex flow ranges or large in cases of simple flow ranges through the configuration control of the mesh density in accordance with each flow characteristic used. 
Table 1 Principal parameters for the KCS

\begin{tabular}{|c|c|c|}
\hline & Ship & Model \\
\hline Scale ratio & \multicolumn{2}{|c|}{$1 / 31.599$} \\
\hline LBP $[\mathrm{m}]$ & 230 & 7.2786 \\
\hline B [m] & 32.2 & 1.019 \\
\hline $\mathrm{T}[\mathrm{m}]$ & 10.8 & 0.3418 \\
\hline$\Delta\left[\mathrm{m}^{3}\right]$ & 52030 & 1.649 \\
\hline $\mathrm{LCG}$ & 111.6 & 3.532 \\
\hline $\mathrm{VCG}[\mathrm{m}]$, from keel & 14.322 & 0.453 \\
\hline $\mathrm{V}_{s}[\mathrm{~m} / \mathrm{s}]$ & $2.572(5 \mathrm{kts})$ & 0.458 \\
\hline$K_{x x} / \mathrm{B}$ & & 0.4 \\
\hline$K_{y y} / \mathrm{LBP}, K_{z z} / \mathrm{LBP}$ & \multicolumn{2}{|}{0.25} \\
\hline
\end{tabular}

The calculation of the spatial gradient of the physical property in a polyhedral grid made according to a trimmed mesh uses the least square method for second order accuracy. Moreover, to simulate the boundary layer flow around the ship surface more accurately, we used the prism layer technique to grid layers with 4.4 million grids from the hull surface by the half-width model ship as shown in Fig. 1. The density of the grid was selected based on the results of 2 dimensional numerical validation.

The generation of the incident wave is an important factor in estimating the slamming pressure accurately. Abdussamie et al. [17, 18] studied the grid dependency on the wave generation and found that more than 30 grids for wave height and 80 grids for wave length were needed to generate the waves well numerically. Therefore, 50 grids for wave height and around 100 grids for the wave length were used in the present numerical simulations.

The numerical calculation used Stokes fifth order wave theory in consideration of the wave height and period. When the motion of the ship is increased, the reflected wave is generated in the direction of FP. As a result, the closer the inlet region is to the ship, the more the reflected waves and the incident waves overlap. It is possible to solve the problem by generating the grid by locating the inlet region far from the ship, but the number of grids is increased excessively.

Kim et al. [19, 20, 21] have solved the problem of reflected waves without increasing the number of girds using Euler Overlay method(EOM). In this study, the Euler Overlay Method (EOM) was applied to simulate waves accurately without numerical damping in the $0.5 \mathrm{~L}$ of inlet region. In addition, a damping zone region was also applied in the region of $0.5 \mathrm{~L}$ from the outlet to reduce the influence of the reflected wave due to generated wave. The velocity on the inlet boundary is determined by adding the ship advancing speed to theoretical wave velocity. In this study, the ship advancing speed is $0.458 \mathrm{~m} / \mathrm{s}$ in model scale. In the regions applied EOM, the difference of the water velocity and target velocity is added to the source term of NavierStokes equations. In the inlet EOM region, the target velocity is sum of ship advancing velocity and wave velocity. In the outlet EOM region, the target velocity is the ship advancing velocity. The k- $\omega$ turbulent model was used and it is one of the most widely used turbulent models for external aero and hydrodynamics. Turbulent specific dissipation rate and turbulent kinetic energy are equal to $1.0 \times 10^{-4}(1 / \mathrm{s})$ and $1.0 \times 10^{-3}(\mathrm{~J} / \mathrm{kg})$, repectively. 

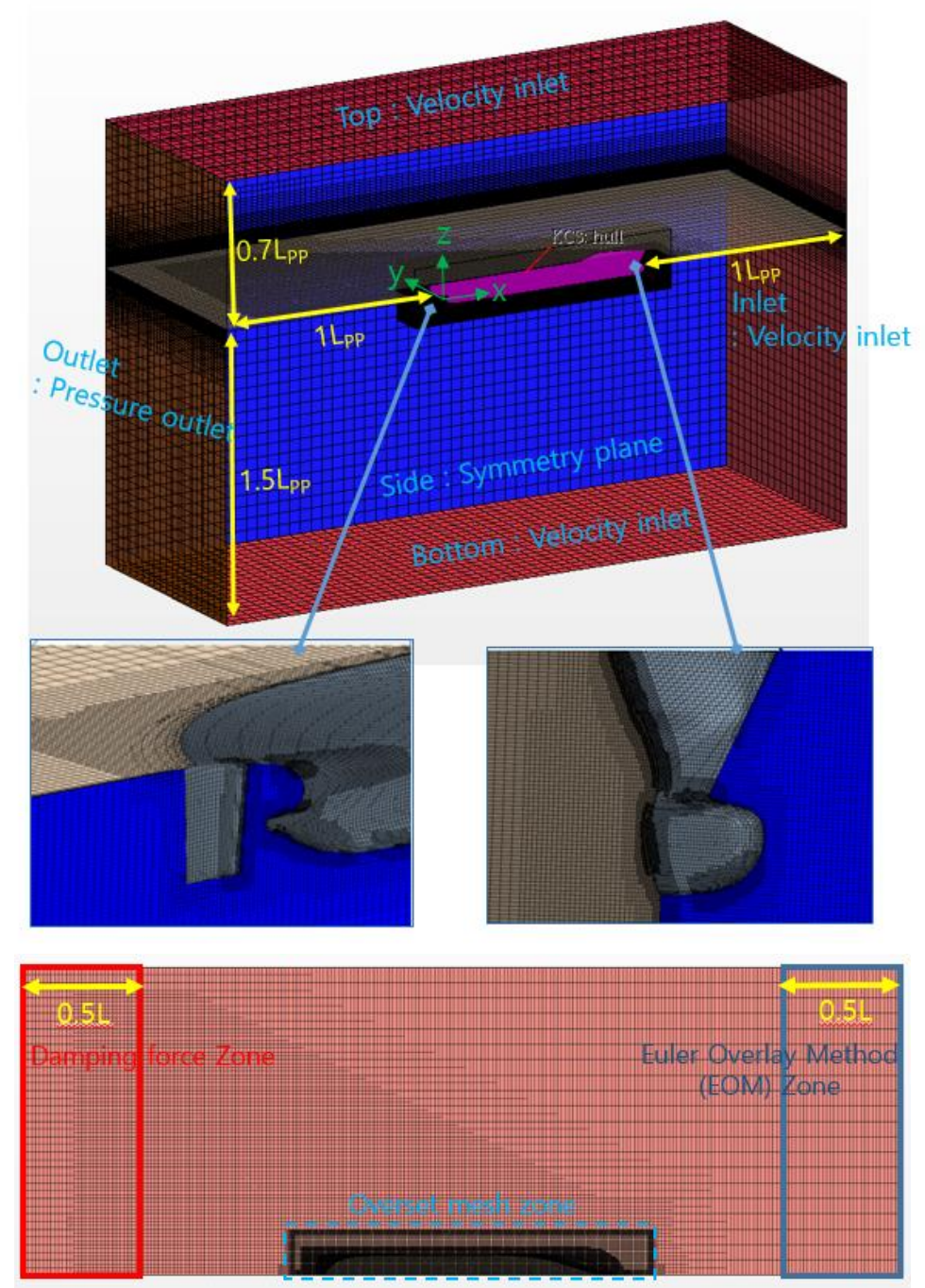

Fig. 1 Grid composition and boundary conditions on the KCS container ship

A symmetric condition was applied to the centre plane, top, bottom and the side of the calculation domain while the wall condition was applied to the surface of the ship. The Volume of Fluid (VOF) method was used to satisfy the free surface boundary conditions reflect the free surface.

A dynamic fluid body interaction (DFBI) scheme was applied to simulate the motion of the ship by the wave. Except for the heave and pitch motions, all other motions were stationary fixed. For more accuracy, an overset grid system was also used to simulate a large ship motion by waves. An overset mesh allows large and complex motions and moving parts to be easily set up and simulated. An overset mesh typically containing a body of interest such as a ship is superimposed on a background mesh containing the surrounding geometry, and data is interpolated between each other the two. The overset mesh system have been often used using by researchers for slamming phenomena or ship motion due to wave [22].

In hash environment, the operators usually reduce the ship speed to decrease the motions and wave loads. The standard velocity for slamming load prediction is suggested the significantly low speed as $0.25 \%$ of design speed when significant wave height is more than $12 \mathrm{~m}$ in ABS rule [23]. In addition, International Maritime Organization (IMO) is considering 
enforcing the minimum power propulsion power to maintain a ship speed of at least 5 knots for ships operating under rough sea conditions [24]. In the present research, the ship advancing speed was set to 5 knots the minimum speed keeping a ship maneuverable.

An equivalent design wave method was used to select the target wave height and the target wave period was considered as relative motion and velocity. Six degrees of freedom motion of the KCS container ship used KR3D owned by KRS, the motion analysis program based on potential theory, owned by the KRS. Based on the calculated motion of the ship, the response amplitude operators(RAOs) were derived for relative motion and velocity of the FP and incident wave (Fig. 1Fig. 2).

The relative motion and relative velocity were the highest generated at wave direction of 120deg, 150deg and 180deg in Fig. 2. Since it is not known which wave direction is generated the maximum slamming pressure, all conditions of wave direction should be considered for nonlinear problems such as slamming.

In the case of a ship with a bulbous, it is known that the greatest slamming pressure is occurred at the head sea condition $\left(180^{\circ}\right)$ due to the bulbous shapes. It has the effect of increasing the angle of attack of flow on hull surface [25]. Hence the wave heading that had the greatest impact on the slamming at the bow flare was selected as incident wave of $180^{\circ}$. However, it is necessary to accurately predict the maximum slamming pressure in various wave directions in future.

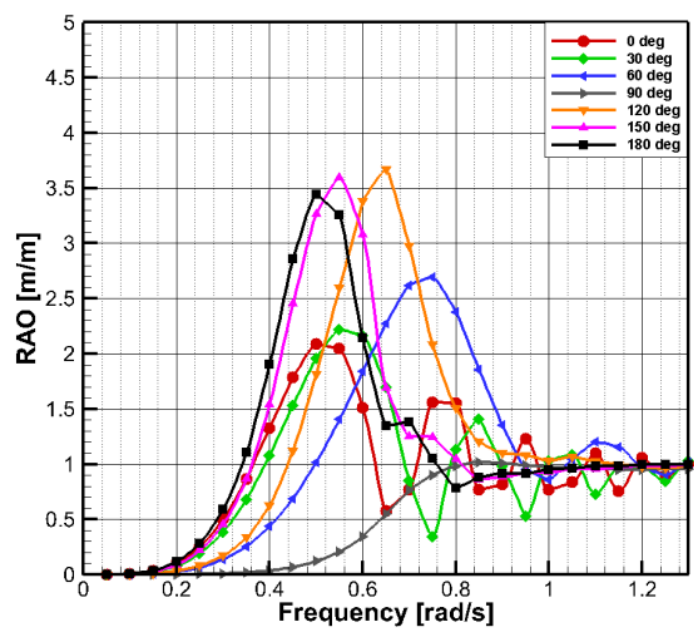

(a)Relative motion

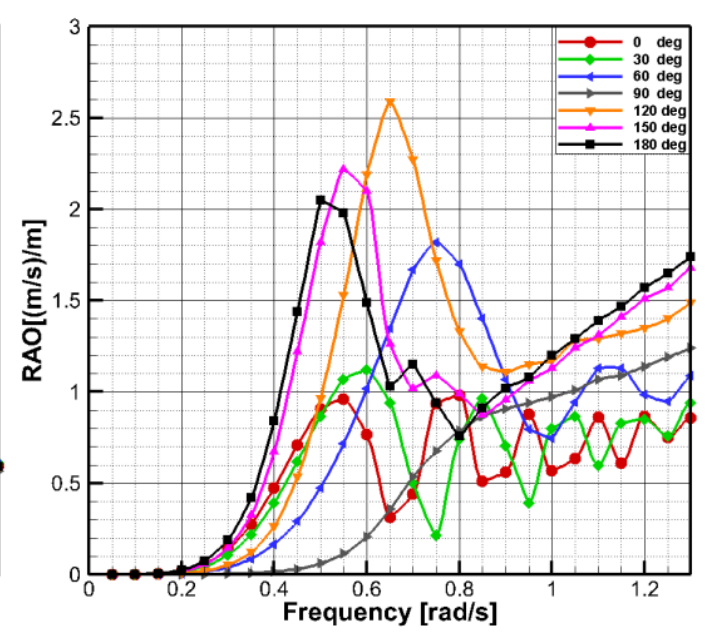

(b) Relative velocity

Fig. 2 RAOs of the relative motion and velocity at bow

To determine the wave height of the incident wave, North Atlantic Standard Wave Data (IACS Rec. No. 34) and PM Spectrum were used to calculate the long term with the probability level of $10^{-8}$ and then divide that by the maximum value of relative motion. Numerical calculation was carried out under the condition of $12.57 \mathrm{~s}$ (wave period), $20.7 \mathrm{~m}$ (wave height) as shown in Table 2 . 
Table 2 Test conditions for slamming simulation

\begin{tabular}{|c|c|}
\hline Ship speed $\left(V_{S}\right)$ & $5 \mathrm{knots}$ \\
\hline Wave height $(\mathrm{H})$ & $20.7 \mathrm{~m}$ \\
\hline Wave period $(\mathrm{T})$ & $12.57 \mathrm{sec}$ \\
\hline Wave heading & $180 \mathrm{deg}$ \\
\hline
\end{tabular}

\section{Validation of the numerical setup}

Impact pressure prediction through the CFD analysis is generally known to be the most influenced by the time interval (dt) and the grid resolution [25]. The time interval is known to be the most dominant factor affecting the impact pressure prediction through the CFD analysis in general. In this study, prior to estimating the slamming pressure on the $3 \mathrm{D}$ vessel, the validity of the numerical calculation was investigated in order to improve the accuracy of the impact pressure estimation on the free fall of a wedge-shaped body with reliable experimental results.

\subsection{Target object}

A wedge-shaped body was selected to examine the validity of numerical setup. The length and breadth of the wedge-shaped body are $800 \mathrm{~mm}$ and $600 \mathrm{~mm}$ as shown in Fig. 3. The deadrise angle of wedge is 30 degrees and the wedge-shaped body was dropped at a point of $0.5 \mathrm{~m}$ from free surface. For the measuring point and further detailed information, refer to Kim et al. [27].

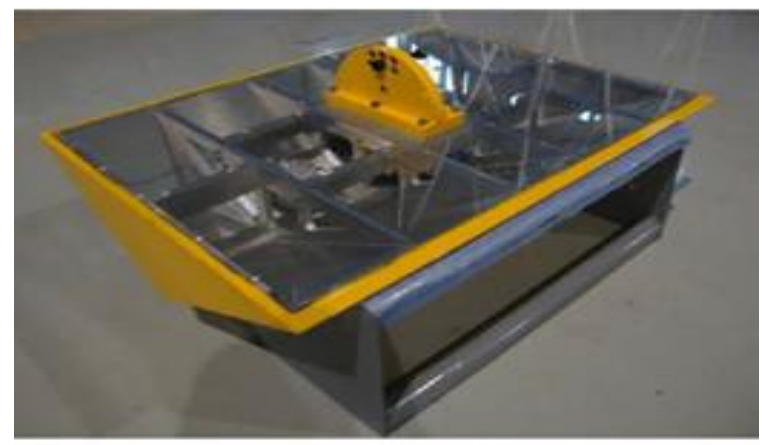

Fig. 3 Experiment on the 2D wedge [27]

\subsection{Influence of the grid size}

A numerical simulation was carried out to investigate the effect of the grid size on the pr ediction of the impact pressure as shown in Fig. 4. The grid size is defined as $B / \mathrm{Y}_{\text {cell. }} \mathrm{B} / \mathrm{Y}_{\text {cell }} \mathrm{O}$ $\mathrm{f}$ the coarse mesh, medium mesh and fine mesh are 60, 120 and 240, respectively, as shown in Table 3. B is the breadth of the wedge-shaped body, and $Y_{\text {cell }}$ is the minimum grid size in the direction of the breadth. The time interval of the numerical simulation is set equal to $5 \times 10^{-5}(2$ $0 \mathrm{kHz}$ ), which is the same value as the measured velocity of the sensor used in the model test. 


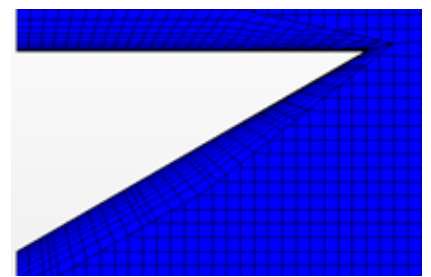

(a) Coarse

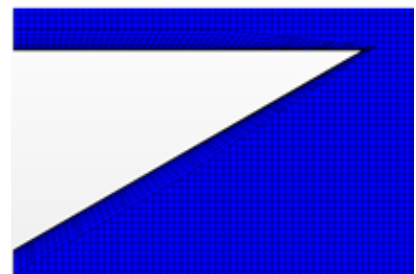

(b) Medium

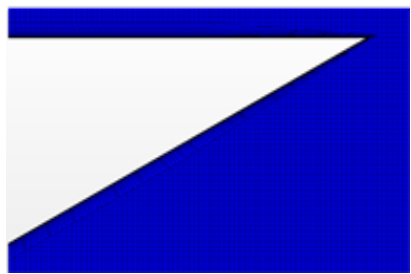

(c) Fine

Fig. 4 Grid system for various numbers of cells

Table 3 Test conditions of the various grid systems

\begin{tabular}{|c|c|c|c|}
\hline & $\Delta \mathrm{x}, \Delta \mathrm{y}[\mathrm{m}]$ & $\mathrm{B} / \mathrm{Y}_{\text {cell }}$ & $\mathrm{dt}[\mathrm{s}]$ \\
\hline Coarse & 0.01 & 60 & \multirow{2}{*}{$5 \times 10^{-5}$} \\
\hline Medium & 0.005 & 120 & \\
\hline Fine & 0.0025 & 240 & \\
\hline
\end{tabular}

The influence of the grid size on the estimation of the impact pressure is shown in Fig. 5 . As shown in the figure, the results of the numerical simulation show that the maximum press ure and characteristics are similar to the experimental results. In all cases of the numerical calc ulations, pressure oscillations were generated as compared to the experiment, but this was bec ause experimental results were processed through a filter. Above the medium grid size, the pe ak pressure value was found to match that of the experimental values within a range of approx imately $3 \%$. However, the point of occurrence of the peak pressure and the absolute value in c ase of coarse mesh were found to be significantly different from those of the experimental res ults. Based on the results of this analysis, the grid size was constructed to be greater than 120 of $\mathrm{B} / \mathrm{Y}_{\text {cell }}$ when calculating the slamming impact pressure of a three-dimensional vessel in this study.

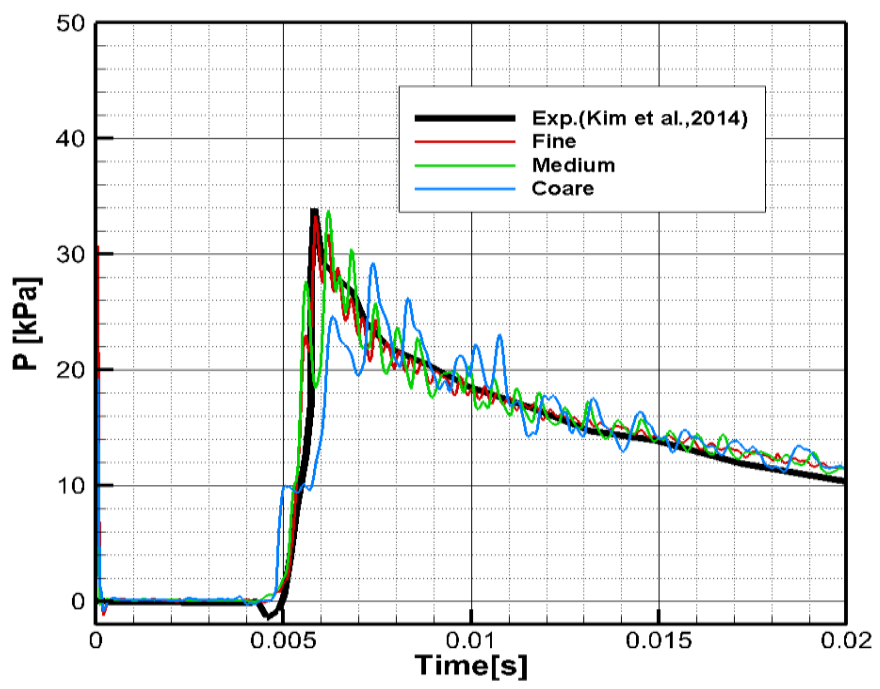

Fig. 5 Comparison of pressure history on various grid systems 


\subsection{Influence of the time interval}

It is known that the estimation of the impact pressure acting on the hull for an extremely short period of time is greatly affected by the time interval in numerical calculation. Therefor e, numerical simulations for four cases were additionally carried out to examine the influence of the time interval on the size and aspect of the impact pressure. From the study on the free fa 11 experiment of a wedge-shaped body by Kim et al. [27], the Courant number is 0.006 when $t$ he time interval is the smallest with approximately $1 \times 10^{-5} \mathrm{~s}$. As such, we performed the calcula tion under four conditions of the Courant number $=0.006$, which divided the rise time by 100 , Courant number $=0.03$ which divided the time step by 20 , Courant number $=0.06$, which divide $\mathrm{d}$ the time interval by 10 , and Courant number $=0.6$, which was the time interval, as shown in Table 4.

Table 4 Test conditions for various the time interval (dt)

\begin{tabular}{|c|c|c|}
\hline $\mathrm{dt}[\mathrm{s}]$ & Courant No. & $\Delta \mathrm{x}, \Delta \mathrm{y}[\mathrm{m}]$ \\
\hline $1 \times 10^{-5}$ & 0.006 & \multirow{2}{*}{0.005} \\
\hline $5 \times 10^{-5}$ & 0.03 & \\
\hline $1 \times 10^{-4}$ & 0.06 & \\
\hline $1 \times 10^{-3}$ & 0.6 & \\
\hline
\end{tabular}

Fig. 6 shows the estimated calculated results of the impact pressure measured over time in the experiment and from the numerical simulation. As seen in the figure, the predicted maxi mum pressure value was considerably lower than the experimental results when the Courant $\mathrm{n}$ umber $=0.06$. However the impact pressure pattern tends to be similar to the results of the mod el test in all cases except for this case. In particular, when the Courant number was lower than 0.03, the maximum impact pressure from the numerical results was in good agreement with th e experimental results quantitatively. When the Courant number was 0.06 , the maximum peak pressure was about $30 \mathrm{kPa}$ and $10 \%$ lower compared to that of the model test, but rise time an $\mathrm{d}$ the duration of pressure from the numerical results were shown to be almost the same as the experiment. From the perspective of the efficiency of the numerical calculation, it was decided that the results of the numerical calculation were also meaningful even when the Courant num ber was 0.06 . As we determined that the case when the Courant number $=0.06$ was also signif icant for the efficiency of the numerical analysis, we used 0.06 for the Courant number to calc ulate the slamming of the ship.

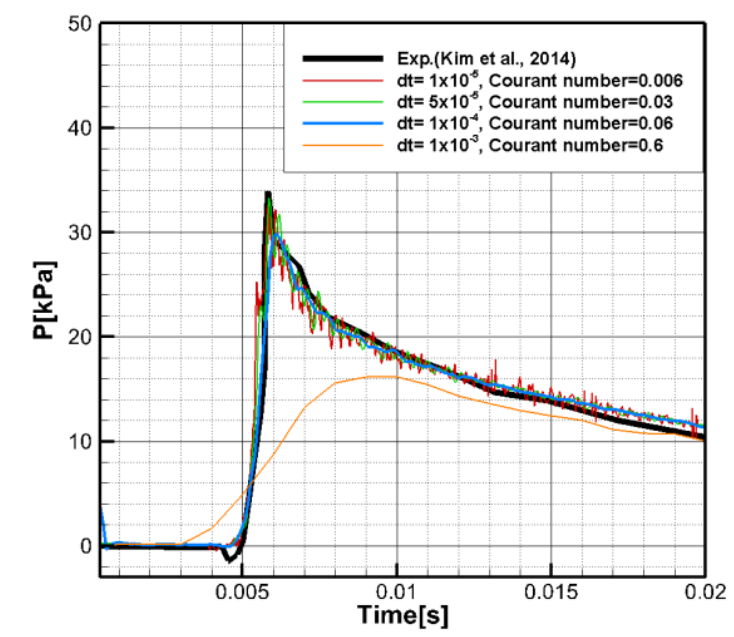

Fig. 6 Comparison of the pressure history on various time intervals 


\section{RESULTS OF THE NUMERICAL CALCULATIONS}

\subsection{Incident wave and ship motion}

In ship operation under the rough sea conditions, the impact pressure is occurred on the hull because of the relative motion with incident waves. Hence, it is necessary to implement accurate incident waves for numerical simulation of slamming phenomena. Fig. 7 compares the wave elevation measured by the present calculation that obtained by a theoretical method at a $0.5 \mathrm{~L}$ distance away from the FP, in the direction of the entrance of the vessel towards the stern. As shown in this figure, it can be confirmed that the incident wave to be generated is properly implemented in numerical simulation. This is because the waveform compensation using the EOM method and the generated grid system has the sufficient grid density per wave length and height.

In this study, motions of the vessel caused by $180^{\circ}$ incident waves were performed in heave and pitch motion as free condition in head sea, as shown in Fig. 8. For the stability of the numerical solution, the motion of the ship was virtually forced for about 2 seconds. The pitch angle and heave motion of the ship change from -6.3 degrees to 7.6 degrees and from $-0.103 \mathrm{~m}$ to $0.046 \mathrm{~m}$ with regular waves, respectively.

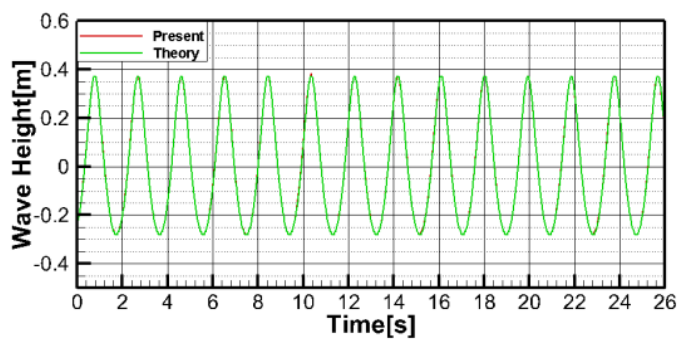

Fig. 7 Comparison of the wave height histories generated by the CFD and theory method (Vs=5knots, H=20.7m, and $\mathrm{T}=12.57 \mathrm{~s}$ )

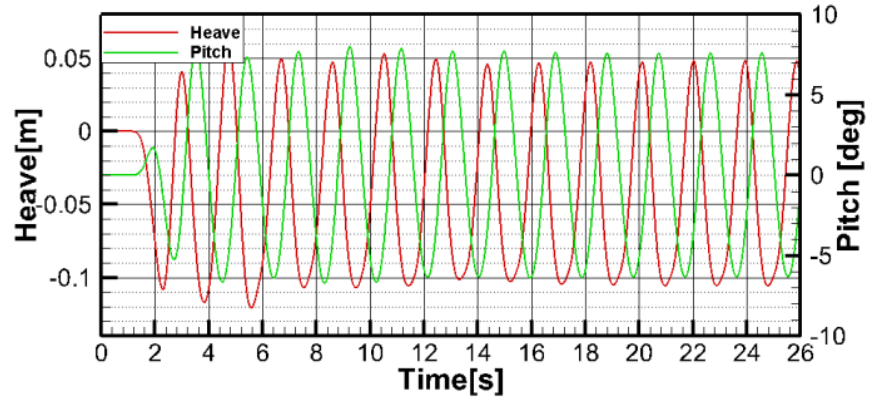

Fig. 8 Time histories of the heave and pitch motion on the KCS ship (Vs=5knots, H=20.7m, and T=12.57s)

\subsection{Bow flare slamming pressure}

As shown in Fig. 9, it was divided into 5 sections from FP to $0.85 \mathrm{st}$, and divided into 5 sections based on the draft to measure the impact pressure. The bow impact pressure was measured at a total of 25 measuring points. 


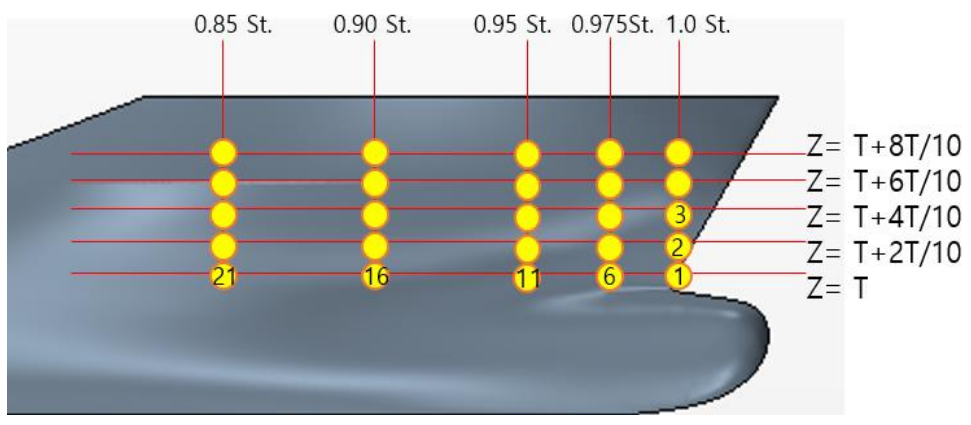

Fig. 9 Pressure measuring points of numerical simulation

Fig. 10 shows the slamming pressure acting on the 25 points as described above. A high impact pressures larger then $10 \mathrm{kPa}$ was mainly observed near the free surface as shown in Fig. 10 (a, b, c). In the upper region, the impact pressures were not high as shown in Fig. 10 (d) and 10(e). The highest peak pressure was measured at FP 12 point around 14.75 seconds.

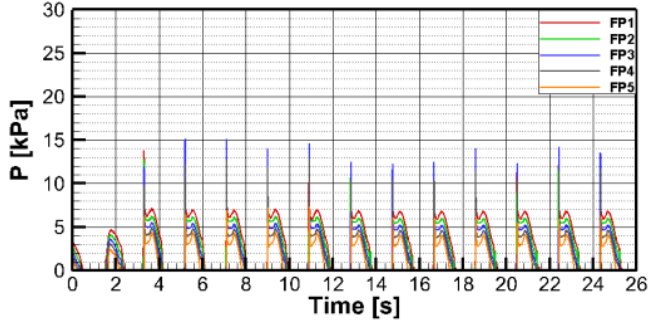

(a) Probe number of $1-5$

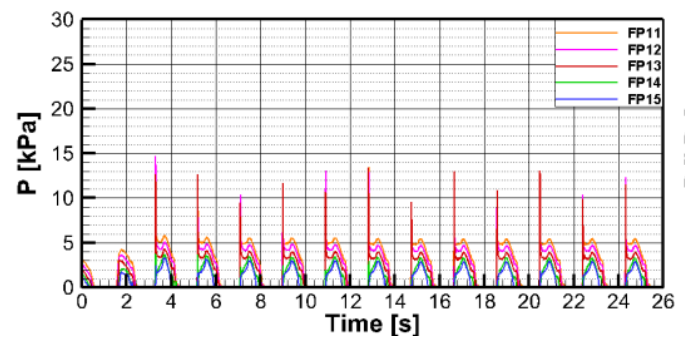

(c) Probe number of $11-15$

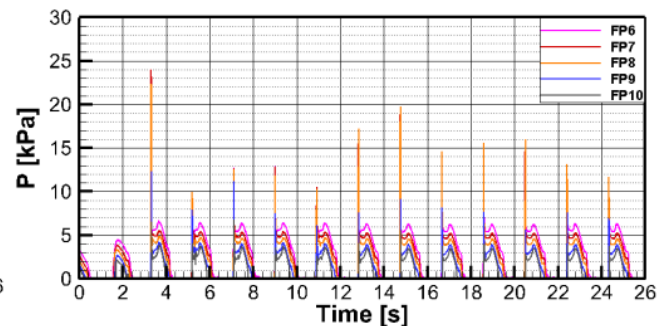

(b) Probe number of 6 - 10

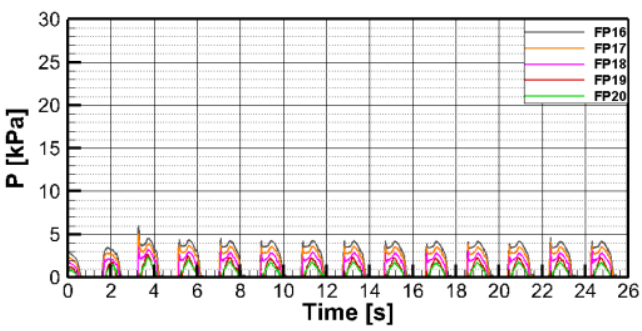

(d) Probe number of 16 - 20

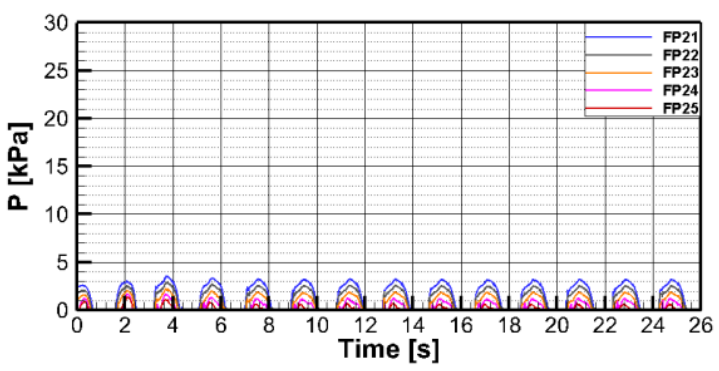

(e) Probe number of $21-25$

Fig. 10 Pressure time history at specific points 
Fig. 11 shows the time history of the pressure at the FP8 point where the maximum peak pressure is observed. As shown in the figure, the impact pressure temporarily increases and th en disappears in region A. In region B, the static pressure is constantly maintained after the im pact pressure has passed. The total duration time of the impact pressure is expressed as the su $\mathrm{m}$ of the rise time $\left(\mathrm{t}_{\text {rise }}\right)$ and drop time $\left(\mathrm{t}_{\text {drop }}\right)$, which is about 0.023 seconds $(0.13 \mathrm{~s}$ in the full sc ale). The duration time of the $\mathrm{B}$ region due to the static pressure is approximately 0.93 second $\mathrm{s}(5.23 \mathrm{~s}$ in full scale). The maximum peak pressure acting on FP8 point is approximately 19.7 $8 \mathrm{kPa}$ and is approximately $625 \mathrm{kPa}$ in the full scale.

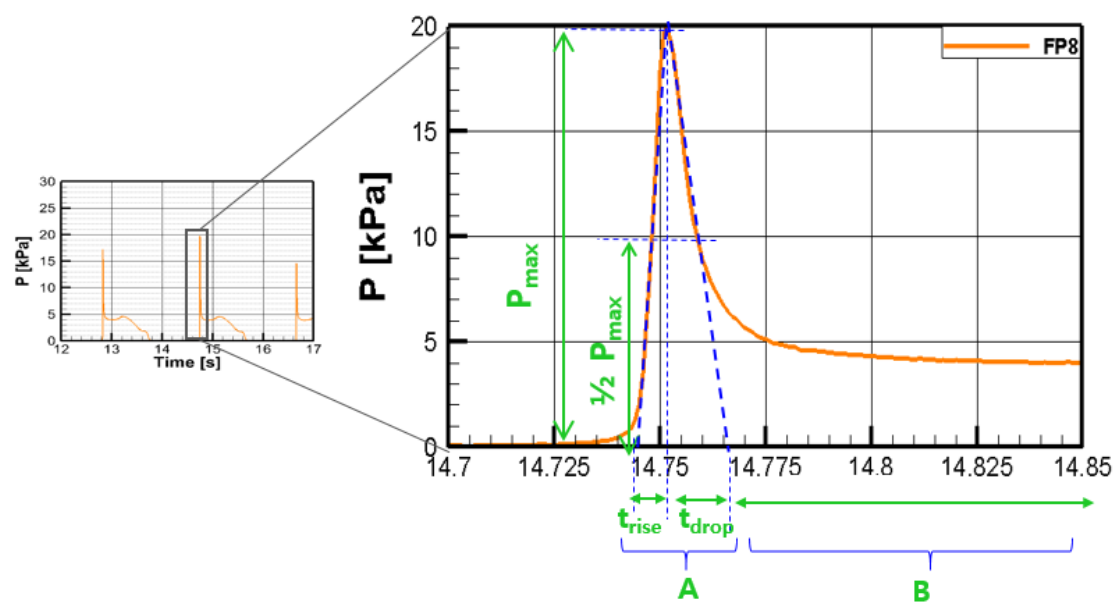

Fig. 11 Pressure time history at FP8

Fig. 12 shows the free surface and hull surface pressures at around 14.75 seconds where the maximum pressure occurs. As the ship descends below the free surface, the impact pressu re on the bow region begins to increase around 14.75s (Fig. 12(b)), and then disappears (Fig. 12(c)). Then only the static pressure remains as the bow descends below the free surface by pi tch motion (Fig. 12(d)).

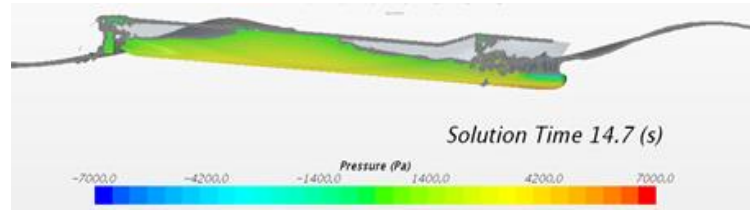

(a) $\mathrm{t}=14.7 \mathrm{~s}$

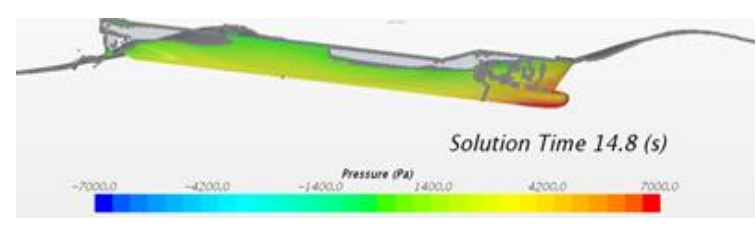

(c) $\mathrm{t}=14.8 \mathrm{~s}$

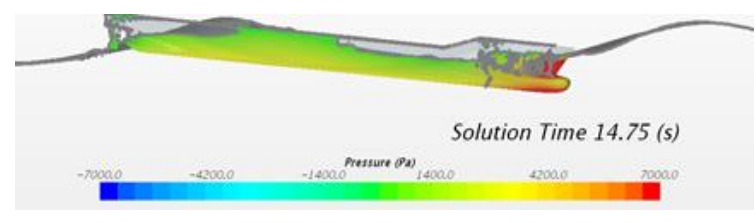

(b) $\mathrm{t}=14.75 \mathrm{~s}$

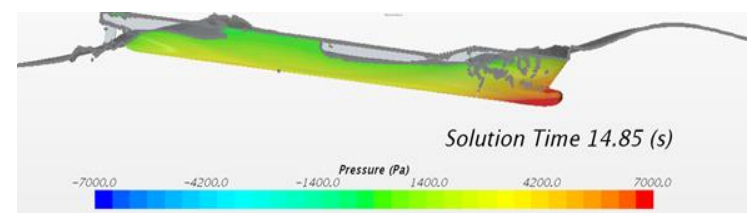

(d) $\mathrm{t}=14.85 \mathrm{~s}$

Fig. 12 Pressure distributions and free surface

Fig. 13(a) shows pressure distributions on the hull surface at 14.75 seconds when the maximum pressure occurs and Fig.13(b) shows the maximum peak pressure on the probe 
points. As the highest impact pressure was generated near the FP 0.975 station as shown in the figure, a structural assessment of this region is necessary.

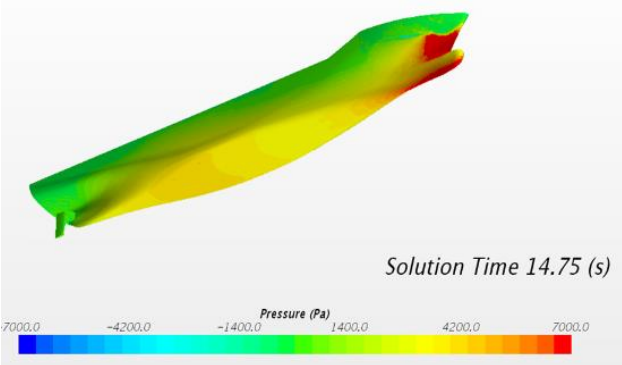

(a) Pressure distributions at $14.75 \mathrm{~s}$

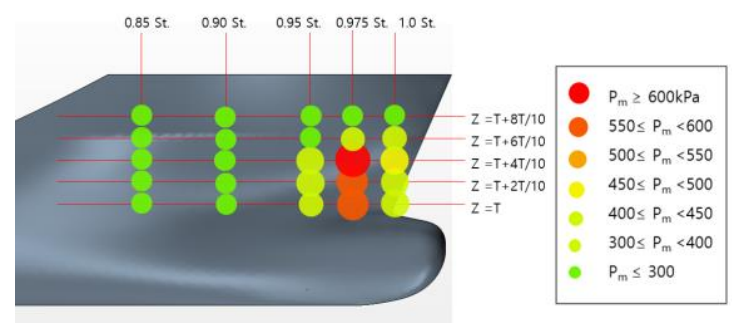

(b) Maximum peak pressure on the probe points

Fig. 13 Pressure distributions on the hull surface

\section{CLASSIFICATION RULES}

\subsection{Slamming pressure formula for each classification}

As shown in Table 5, each classification has proposed a formula of the slamming pressu re acting on the hull. All formulas of the classification adequately take into account the waterentry impact pressure due to vertical relative motion and the breaking wave impact pressure $d$ ue to the velocity component in the forward direction. In this study, the slamming pressure by IACS, ABS, BV, DNV, LR, and NK were compared with and reviewed the present calculatio $\mathrm{n}$ results.

Table 5 Categorization of the slamming formula in the classification

\begin{tabular}{|c|c|c|c|c|}
\hline Class & Rule & Bow flare & Bottom & Stern \\
\hline IACS & Bulk, Tanker & O & O & - \\
\hline ABS & Container & O & O & - \\
\hline BV & Container & O & O & O \\
\hline DNV & Ships & O & O & O \\
\hline LR & Ships & O & O & O \\
\hline NK & Steel ship & O & O & - \\
\hline
\end{tabular}

The common structural rule (CSR) in the international classification society defines the bow sl amming pressure equation as shown in Eq (1). The CSR is a common rule developed for cargo ships and tankers, but it was also applied to container ships for relative comparison and analy 
sis [28]. The main feature for the slamming pressure prediction is the longitudinal bow flare $\mathrm{i}$ mpact pressure distribution factor $\left(f_{F B}\right) . f_{F B}$ is from 0.55 to 1.0 depending on the considered lo ngitudinal position. $V_{\text {im }}$ represents impact velocity, which is a function of LBP, Vs, and the wa terline angle. $\gamma_{w l}$ means the local bow impact angle derived from flare angle and water line ang le.

$$
P_{F B}=1.025 f_{F B} C_{F B} V_{\mathrm{im}}^{2} \sin \gamma_{\mathrm{wl}}
$$

where,

$f_{F B}$ : longitudinal bow flare impact pressure distribution factor

$V_{\text {im }}:$ impact speed

$$
=0.514 V_{r e f} \sin \alpha_{w l}+\sqrt{L}
$$

$C_{F B}$ : coefficient on considering point

$\gamma_{w l}:$ local bow impact angle

$$
=\tan ^{-1}\left(\tan \beta_{p l} / \cos \alpha_{w l}\right)
$$

$\alpha_{w l}:$ flare angle at the calculation point

$\beta_{p l}$ : water line angle at the calculation point

The rule of the ABS classification provides an empirical formula of the bow flare slamming pr essure due to wave, and also provides the bow flare slamming pressure as shown in Eq. (2) [2 9]. $M_{V i}$ is a function of LBP, Vs, and $C_{b} ; K_{i j}$ is a function of the waterline angle and flare angle . Unlike other classification rules, the breadth $\left(B_{\mathrm{i}}\right)$ at the considered point is reflected, and this uniquely requires the breadth of the bow shape.

$$
\begin{aligned}
& P_{i j}=P_{o i j} \text { or } P_{b i j} \\
& P_{o i j}=k_{1}\left(9 M_{R i}-h_{i j}^{2}\right)^{1 / 2} \\
& P_{b i j}=k_{2} k_{3}\left\{C_{2}+K_{i j} M_{V i}\left[1+E_{n i}\right]\right\}
\end{aligned}
$$

Where,

$$
\begin{aligned}
k_{1} & =9.807 \\
k_{2} & =1.025 \\
k_{3} & =1 \text { for } h_{i j} \leq h_{b}{ }^{*} \\
& =1+\left(h_{i j} / h_{b}{ }^{*}-1\right)^{2} \text { for } h_{b}{ }^{*}<h_{i j}<2 h_{b}{ }^{*} \\
& =2 \text { for } h_{i j} \geq 2 h_{b}{ }^{*} \\
C_{2} & =39.2 \mathrm{~m} \\
M_{\mathrm{vi}} & =B_{i} M_{\mathrm{Ri}}\left(M_{\mathrm{Ri}}=c_{1} A_{\mathrm{i}}\left(V L / C_{\mathrm{b}}\right)^{1 / 2}\right. \\
K_{\mathrm{ij}} & =f_{\mathrm{ij}}\left[r_{\mathrm{j}} /\left(b b_{\mathrm{ij}}+0.5 h_{\mathrm{ij}}\right)\right]^{3 / 2}\left[l_{\mathrm{ij}} / r_{\mathrm{j}}\right]\left[1.09+0.029 V-0.47 C_{b}\right]^{2} \\
f_{\mathrm{ij}} & =\left[90 / \beta_{\mathrm{ij}}-1\right]^{2}\left[\tan ^{2}\left(\beta_{\mathrm{ij}}{ }^{\prime}\right) / 9.86\right] \cos \gamma \\
E_{\mathrm{ni}} & =\log n_{\mathrm{ij}} \\
n_{\mathrm{ij}} & =5730\left(M_{\mathrm{vi}} / M_{\mathrm{ri}}\right)^{1 / 2} G_{\mathrm{ij}} \geq 1.0
\end{aligned}
$$


The rule of the BV classification provides an empirical formula of the bow flare slammi ng pressure as shown in Eq (3). The feature of this formula is that the characteristics of a struc tural part $\left(C_{S}\right)$ are considered when calculating bow flare slamming pressure, but the length, di rection, and location have no relation to the slamming pressure [30]. The coefficient $\left(C_{z}\right)$ that $r$ eflects the upward position is applied to consider relative motion, but the vessels of this study have all constant values.

$$
P_{F I}=C_{S} C_{Z}(0.22+0.15 \tan \alpha) \times(0.4 V \sin \beta+\sqrt{L})^{2}
$$

Where,

$C_{\mathrm{s}}=1.8$ for plating and ordinary stiffeners

$=1.0$ for primary supporting members

$C_{\mathrm{Z}}=H-0.5\left(z-T_{\mathrm{LC}}\right)$ for $z \geq 2 H+T_{\mathrm{LC}}-11$

$=5.5$ for $\mathrm{z}<2 H+T_{\mathrm{LC}}-11$

$H$ : Wave parameter

$\alpha$ : flare angle at the calculation point

$\beta$ : water line angle at the calculation point

Equation 4 is the empirical formula of the bow flare slamming pressure in the DNV classificat ion and is similar to the rule of BV. $C_{f}$ is the factor that reflects the roll and pitch angle of the $\mathrm{s}$ hip, and design load of rule should be referred to [31].

$$
P_{s l}=C\left(2.2+C_{f}\right) \times(0.4 V \sin \beta+0.6 \sqrt{L})^{2}
$$

where,

$C=0.18\left(C_{\mathrm{w}}-0.5 h_{\mathrm{o}}\right)$, maximum 1.0

$C_{\mathrm{w}}$ : wave coefficient

$h_{\mathrm{o}}$ : vertical distance $(\mathrm{m})$ from the waterline at draught

$C_{f}=1.5 \tan (\alpha+\gamma)$, maximum 4.0

$\gamma=0.4(\varphi \cos \beta-\theta \sin \beta)$

$\alpha$ : flare angle at the calculation point

$\beta$ : water line angle at the calculation point

In the LR classification, the empirical formula of the bow flare slamming pressure is pro vided as shown in Eq. (5). The formula is a function of the coefficient considering the bow sha pe and the relative vertical velocity [32].

$$
P_{b f}=0.5\left(K_{b f} V_{b f}^{2}+K_{r v} H_{r v} V_{r v}^{2}\right)
$$


Where,

$K_{b f}:$ hull form shape coefficient for wave impacts

$$
\begin{aligned}
& =\pi / \tan \psi \text { for } \psi \geq 10 \\
& =28(1-\operatorname{tam}(2 \psi)) \text { for } \psi<10
\end{aligned}
$$

$\psi:$ effective deadrise angle

$V_{b f}:$ threshold velocity for wave impact

$$
=\frac{\sqrt{10}}{\cos \alpha_{P}}
$$

$K_{r v}:$ hull form shape coefficient for impact due to forward speed

$$
\begin{aligned}
& =\pi / \tan \left(90-\alpha_{p}\right) \text { for } \alpha_{p} \leq 80 \\
& =28\left(1-\tan \left(2\left(90-\alpha_{p}\right)\right)\right) \text { for } \alpha_{p}>80
\end{aligned}
$$

$H_{r v}$ : relative wave heading coefficient

The empirical formula of the bow slamming pressure in the NK classification is defined as shown in Eq. (6) [33].

$$
P=\frac{1}{2} \rho C_{e} K_{P}\left(\frac{v_{n}}{\cos \beta_{0}}\right)^{2}
$$

Where,

$\beta_{0}$ : relative impact angle between wave surface and a point under consideration on ship's surface

$$
\begin{aligned}
& =\Phi-\Phi_{b} \\
& \Phi=\tan -1\left(1 / \tan \beta_{k} \cos \gamma\right) \\
& C_{e}=\beta_{0} / 40+0.25 \text { for } \beta_{0} \leq 30^{\circ} \\
& =1.0 \text { for } \beta_{0}>30^{\circ} \\
& v_{n} \text { :Maximum relative velocity }
\end{aligned}
$$

\subsection{Comparison of the bow flare slamming pressures}

The empirical formula in various classifications provide the quasi static pressure withou t impact pressure. Hence, it is unreasonable to compare the maximum impact pressure calculat ed in CFD with the quasi static pressure calculated using the empirical formula. Though it is $d$ ecided insignificant to make the direct comparison of the absolute value of the quasi-static pre ssure proposed by a classification with the maximum value of the dynamic pressure derived fr om numerical calculations, the maximum value of the dynamic pressure from the numerical ca lculations and the slamming pressure are shown in Fig. 14, to observe qualitative characteristi $\mathrm{cs}$ in investigating the tendency of the slamming pressure on the hull. 


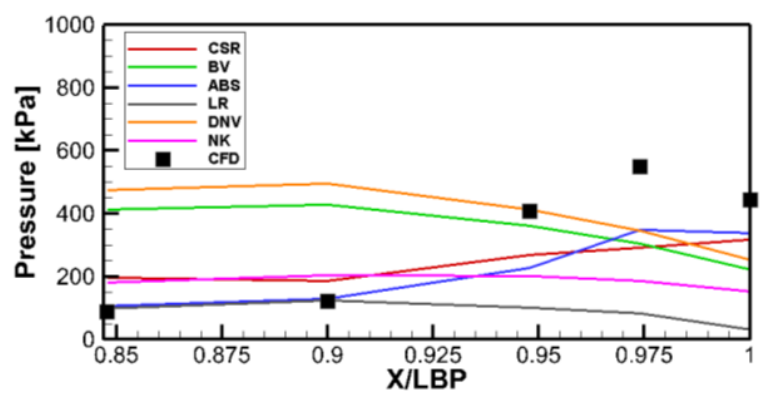

(a) Slamming pressure at $\mathrm{Z}=\mathrm{T}+2 \mathrm{~T} / 10$

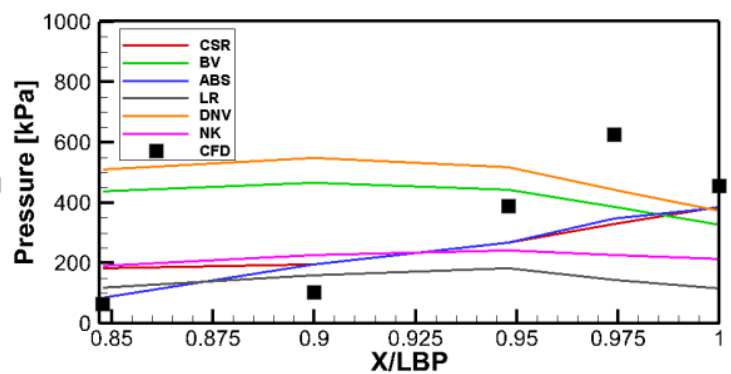

(b) Slamming pressure at $\mathrm{Z}=\mathrm{T}+4 \mathrm{~T} / 10$

Fig. 14 Comparison of the slamming pressure calculated various formulas of the classifications

The numerical results show that the bow flare slamming pressure increases from $0.9 \mathrm{St} t$ o FP and the maximum impact pressure is generated at $0.975 \mathrm{St}$.. The tendency of the pressure to increase towards the forward direction was similar to the results of ABS and CSR. Except $f$ or other results of the ABS and CSR rule, it is found that the slamming pressure is rather decre ased in the direction of the FP, which demonstrated a relatively different tendency from the re sults of the numerical calculations.

\section{CONCLUSION}

Prior to a numerical simulation on a container ship, a numerical calculation was conduct ed to examine the validities of the numerical code on a reliable model test. A numerical simula tion was performed to predict the bow slamming pressure on the container ship under extreme wave conditions $(\mathrm{H}=20.47 \mathrm{~m}, \mathrm{~T}=12.57 \mathrm{~s})$ and these results were compared to the empirical for mulas of different classifications.

1) In order to obtain relatively quantitative numerical calculation results, the grid density $\left(\mathrm{B} / \mathrm{Y}_{\text {cell }}\right)$ should be 120 or greater, and the Courant number should be 0.06 or smaller

2) The position that generated the maximum impact pressure is around 0.975St., and the maximum impact pressure is measured momentarily at FP8 near the bow region. The maximum peak pressure acting on the FP8 point is approximately $19.78 \mathrm{kPa}$ and is ap proximately $625 \mathrm{kPa}$ in the full scale. The duration time of the impact pressure is 0.13 seconds in the full scale. The static pressure continues to act as the bow descends bel ow free surface by pitch motion.

3) Though it is unreasonable to directly compare the absolute value of the quasi-static pr essure proposed by a classification with the maximum value of the dynamic pressure derived from numerical calculations, from the point of view of qualitative tendency, $t$ he results of the ABS, and CSR classification showed that the impact pressure was si gnificantly increased in the FP direction as the results of the numerical simulation.

In this study, the numerical simulation was performed under one wave condition (head sea) in order to predict the bow flare slamming pressure of the KCS ship. Since slamming 
phenomenon has a high nonlinearity, it is not known under which conditions the maximum slamming pressure will be generated. Hence it is necessary to carry out additional calculation in various wave conditions and ship speed in future

\section{REFERENCES}

[1] Von Kármàn, T.: The impact on sea plane floats during landing. National Advisory Committee for Aeronautics. Technical Note No 321, 1929, pp. 309-313.

[2] Wagner, H.: Uber Stossund Gleitvergange an der Oberflache von Flussigkeiten. Z. Angew. Mathematik and Mechanik. Vol. 12, 1932, pp. 193-215. https://doi.org/10.1002/zamm.19320120402

[3] Dobrovol'skaya, Z.N.: On some problems of similarity flow of fluids with a free surface. Journal of Fluid Mechanics. Vol. 36, 1969, pp. 805-829. https://doi.org/10.1017/S0022112069001996

[4] Zhao, R. and Faltisen, O.: Water entry of arbitrary axisymmetric bodies with and without flow separation. The 22nd Symposium on Naval Hydrodynamics, Washington D.C., USA, 1998, pp. 652-664.

[5] Muzaferija, S., Peric M., P., Sames, P. and Schellin, T.: A two fluid Navier-Stokes solver to simulate water entry, The 22nd Symposium on Naval Hydrodynamics, Washington D.C., USA, 1998, pp. 638-651.

[6] Wang, R., Faltinsen, O.M. and Aarsnes, J.V.: Water entry of arbitrary two-dimensional sections with and without flow separation, The 21st Symposium on Naval Hydrodynamics, 1996, pp. 408-423.

[7] Hong, S.Y., Kim, K.H., Kim, B.W. and Kim, Y.S.: Experimental study on the bow-flare slamming of a 10,000 TEU containership, Proc. the 24th Int. Ocean and Polar Engineering Conference, Busan, Korea, 2014 ,

[8] Hong, S.Y., Kyoung, J.H., Kim, Y.S., Song, K.H., Kim, S., Malenica, S., Lindergren, M., Rathje, H. and Ge, C.: Validation of wave loads on a large container ship in oblique waves, The 6th Osaka Colloquium on Seakeeping and stability of ships, Osaka, 2008, pp 109-117

[9] Wang, S. and Soares, C.G.: Analysis of the water impact of symmetric wedges with a multi-material Eulerian formulation. International Journal of Maritime Engineering, 154 (A4), 2012, pp. 191-206.

[10] Wang, S. and Soares, C.G.: Slam induced loads on bow-flared sections with various roll angles. Ocean Engineering, Vol. 67, 2013, pp. 45-57. https://doi.org/10.1016/j.oceaneng.2013.04.009

[11] Lee, S. and Lew, J.: Numerical computations of impact forces acting on breakwater plate of bow deck of container carrier, J. the Society of Naval Architects of Korea, Vol. 52, No:3, 2015, pp.198-205. https://doi.org/10.3744/SNAK.2015.52.3.198

[12] Kim, K., Shin, Y.S. and Wang, W.: A stern slamming analysis using three-dimensional CFD simulation. The 27th International Conference on Offshore Mechanics and Arctic Engineering, Estoril Portugal, 2008. https://doi.org/10.1115/OMAE2008-57805

[13] Rahaman, M.M., Zheng, K. and Akimoto, H.: Numerical Investigation of Bow Slamming on Ships with Large Flare, Proceedings of International Conference on Marine Technology (MARTEC), Bangladesh, 2010, pp. 113-121.

[14] Chen, C.R. and Chen, H.C.: CFD simulation of Extreme Slamming on a Containership in Random Waves, The 24th International Ocean and Polar Engineering Conference, June 15-20, 2014, Korea

[15] Wang S. and Soares, C.G.: Stern slamming of chemical tanker in irregular head waves, Ocean Engineering, Vol. 122, 2016, pp. 322-332. https://doi.org/10.1016/j.oceaneng.2016.05.013

[16] ABS, 2002. A Direct Calculation Approach for Designing a ship-shaped FPSO's Bow Against Wave Slamming Load, Technical Report

[17] Abdussamie, N., Amin, W., Ojeda, R., Thomas, G. and Drobyshevski, Y.: Vertical wave-in-deck loading and pressure distribution on fixed horizontal decks of offshore platforms. The 24th International Offshore and Polar Engineering, 2014, Busan, South Korea.

[18] Abdussamie, N., Ojeda, R., Amin, W., Thomas, G. and Drobyshevski, Y.: Prediction of wave-in-deck loads on offshore structures using CFD. The 19th Australasian Fluid Mechanics Conference, Melbourne, Australia, 8-11, December, 2014.

[19] Kim, J. W., Kyoung, J. H., Ertekin, R. C. and Bai, K. J.: A Finite-Element Computation of WaveStructure Interaction between Steep Stokes Waves and Vertical Cylinders Journal of Waterway, Port, Coastal and Ocean Engineering, Vol. 132, No. 5, pp 337-347, 2006.

[20] Kim, J.W., O'Sullivan, J. and Read A.: Ringing Analysis of a Vertical Cylinder by Euler Overlay Method, OMAE2012 84091, Riode Janeiro, Brazil, June 2012. 
[21] Kim, J.W., Jang, H., Baquet, A., O'Sullivan, J., Lee, S., Read, A. and Jasak H.: Technical and Economic Readiness Review of CFD-Based Numerical Wave Basin for Offshore Floater Design, OTC 201627294 , Houston, USA,May 2016.

[22] Ock, Y.B.: Numerical Simulations of Added Resistance around Ships in Regular Head Waves using Overset Grids, Master's thesis, Department of Naval Architecture and Ocean Engineering, Pusan National University, 2014.

[23] ABS, 2011. Guide for Slamming Loads and Strength Assessment for Vessel, American Bureau of Shipping

[24] IMO: 2013 Interim Guidelines for Determining Minimum Propulsion Power to Maintain The Manoeuvrability of Ships in Adverse Conditions, MEPC. 1/Circ. 850/Rev. 1, July, 2015

[25] Rahaman M.M. and Akimoto, H., "Analysis of the Mechanism of Slamming on the Bow Flare Region of a Container Ship by Using RaNS CFD Method”, 22nd International Ocean and Polar Engineering Conference, June 17-23, 2012, Rhodes, Greece.

[26] Peric, M. and Zorn, T.: Simulation of sloshing loads on moving tanks, $24^{\text {th }}$ International Conference on Offshore Mechanics and Artic Engineering, 12-17 June, Halkidiki, Greece, 2005, OMAE2005-67581. https://doi.org/10.1115/OMAE2005-67581

[27] Kim, K.H., Lee, D.Y., Hong, S.Y., Kim, B.W., Kim, Y.S. and Nam, B.W.: Experimental study on the water impact load on symmetric and asymmetric wedges, The $24^{\text {th }}$ international Ocean and Polar Engineering Conference, 15-20 June, Busan, Korea, 2014, ISOPE-I-14-336.

[28] IACS: Common Structural Rules for Bulk Carriers and Oil Tankers, Part 1, Chapter 4, Section5, 2014.

[29] ABS: Rules for building and classing Steel Vessels, Part 5C, Section 3, 2016.

[30] BV: Structure Rules for Container ships, Ch 4, Section 5, 2017.

[31] DNV-GL: Rule for Classificaion of Ships- Hull structural design Ships with length 100 meters and above Pt.3 Ch. 1, Sec. 7, 2016.

[32] LR: Rules and Regulations for the classification of Naval Ships, Part 4, Chapter 2, Section 4, 2017.

[33] NK: Rules for the Survey and Construction of Steel Ships, Part C, Chapter 6, 2016.

Submitted: 10.06.2018. Daewon Seo,dwseo@krs.co.kr

Ship \& Offshore Technology Center, Korean Register, Republic of Korea

Accepted: $\quad$ 03.01.2019. Kwang-Leol Jeong, kl.jeong@nextfoam.co.kr

Research center, NEXTfoam Co., Ltd., Republic of Korea 